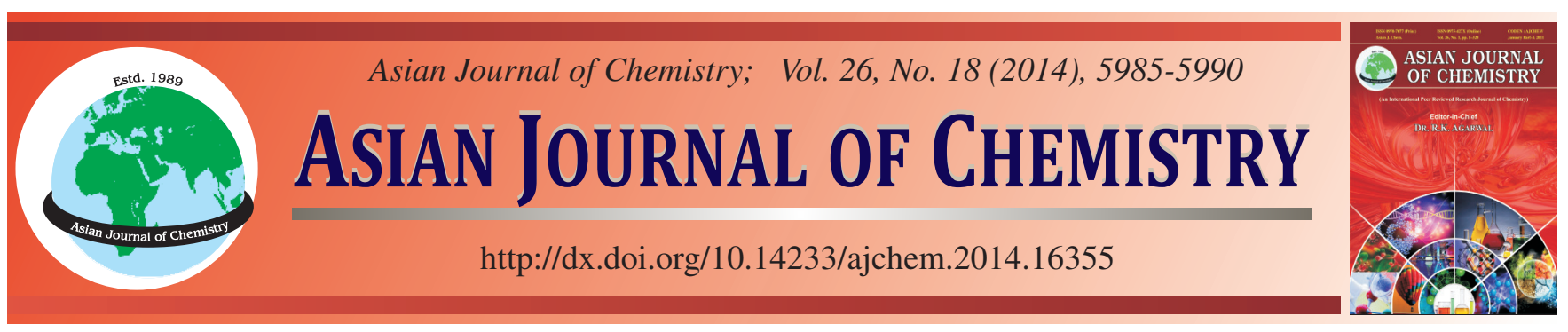

\title{
Comparison of Flavonoid Contents between Common and Tartary Buckwheat (Fagopyrum) Sprouts Cultured with/without Soil
}

\section{Mariadhas Valan Arasu ${ }^{1}$, Sun-Ju Kim ${ }^{2, *}$, Naif Abdullah Al-Dhabi ${ }^{1, *}$,Tatsuro SuZuki ${ }^{3}$, Hiroaki Yamauchi ${ }^{4}$ and SAng-Won LeE $^{5}$}

${ }^{1}$ Department of Botany and Microbiology, Addiriyah Chair for Environmental Studies, College of Science, King Saud University, P. O. Box 2455, Riyadh 11451, Saudi Arabia

${ }^{2}$ Department of Bio-Environmental Chemistry, Chungnam National University, 99 Daehak-Ro, Yuseong-Gu, Daejeon 305-764, Republic of Korea ${ }^{3}$ National Agricultural Research Center for Hokkaido Region, Shinsei, Memuro, Kasai-Gun, Hokkaido 082-0081, Japan

${ }^{4}$ Department of Food Science, Obihiro University of Agriculture and Veterinary Medicine, West 2-11, Inada, Obihiro, Hokkaido 080-8555, Japan ${ }^{5}$ Herbal Crop Research Team, International Institute of Horticultural \& Herbal Science, RDA, Eumseong-gun, Chungcheongbuk-do 369-873, Republic of Korea

*Corresponding author: Fax: +82 42 8217142; Tel: +82 42 8216738; E-mail: kimsunju@ @nu.ac.kr

\begin{abstract}
Buckwheat has been used as a traditional food and medicine in China, Japan and Korea. Phenolic compounds including chlorogenic acid, orientin, isoorientin, vitexin, isovitexin, rutin and quercetin were quantified with their commercial standards using high performance liquid chromatography (HPLC) in dry weight in 'Hokkai T10', 'Hokkai T8' and 'Kitawase' sprouts. The highest total phenolic content mean $48.76 \mathrm{mg} \mathrm{g}^{-1}$ dry weight was found in 'Hokkai T9' sprouts followed by mean 40.76, 38.09, $37.67 \mathrm{mg} \mathrm{g}^{-1}$ dry weight in 'Hokkai T10', 'Hokkai T8' and 'Kitawase' sprouts, respectively, with soilless practice at 10 DAS. The major metabolites found in common buckwheat sprouts were orientin, isoorientin, vitexin, isovitexin, rutin, but only rutin in Tartary buckwheat sprouts. In particular, rutin content in soilless-grown sprouts (mean 33.59 and $47.93 \mathrm{mg} \mathrm{g}^{-1}$ dry weight in 'Hokkai T 8' and 'Hokkai T 9', respectively) at 10 DAS was 20-40 \% higher than that at 7 DAS.
\end{abstract}

Keywords: Flavonoids, Rutin, Seed sprouts, Soilless practice, Tartary buckwheat.

\section{INTRODUCTION}

Buckwheat (Fagopyrum spp.) belongs to the Polygonaceae family and is one of the traditional crops cultivated in various countries such as Brazil China, India, Japan, Korea, Poland, Russia and United States ${ }^{1}$. Due to its nutritional excellence of lysine, GABA ( $\gamma$-amino- $n$-butyric acid) and sulphur containing amino acids (methionine and cystine), buckwheat has been receiving great attention as an alternative crop to major cereals such as wheat and corn ${ }^{2}$. Common (Fagopyrum esculentum Moench) and Tartary (F. tataricum Gaertn.) buckwheats are the most widely grown buckwheat species and over $1.78 \times$ $10^{6}$ tones of buckwheat over $2 \times 10^{6}$ ha were produced worldwide $^{3}$. Buckwheats are abundant in nutrients, such as carbohydrates, protein and minerals. Compared to seeds of rice and wheat, buckwheat seeds are richer in starch, protein, minerals like $\mathrm{Fe}, \mathrm{Zn}$ and $\mathrm{Se}^{4}$. Moreover, they contain adequate levels of important micronutrients such as variety of vitamins and significant amount of other bioactive components such as polyphenols, saponins, phytosterols, squalene and fagopyritols ${ }^{5}$. Buckwheat is the only cereal among the genus
Fagopyrum that contains rutin. Hence, it is a beneficial source of flavonoids ${ }^{6}$. Other phenolic compounds and flavones such as hyperin, quercitrin and quercetin also present in immature buckwheat seeds ${ }^{7}$. In addition, buckwheat seeds are also naturally gluten-free and thus, they are currently emerging as healthy alternatives to gluten-containing grains in the glutenfree $\operatorname{diet}^{8}$.

Polyphenols are secondary plant metabolites that play a role in the protection of plants against ultraviolet radiation, pathogens and herbivores 9 . Several hundred molecules with polyphenol structure have been identified in edible plants ${ }^{10}$. Current estimated intake of polyphenols is $>100 \mathrm{mg}$ /day which is in contrast with the intake of important vitamins such as vitamin $\mathrm{E}$ (8.5), vitamin $\mathrm{C}$ (80) and $\beta$-carotene $(1.9 \mathrm{mg} / \mathrm{day})^{11}$. This suggests that these compounds represent an important part of the total dietary intake of biologically active metabolites. In particular, rutin is used to reduce capillary fragility associated with some hemorrhagic diseases or hypertension in humans ${ }^{12}$. Quercetin (aglycone of rutin), a major bioflavonoid of human diet, present in buckwheat, has been identified as a strong antioxidant, anti-angiogenesis and anticancer properties ${ }^{13}$. It 
TABLE 1

DIFFERENT PHENOLIC COMPOSITIONS ISOLATED FROM THE SEED SPROUTS OF COMMON AND TARTARY BUCKWHEAT

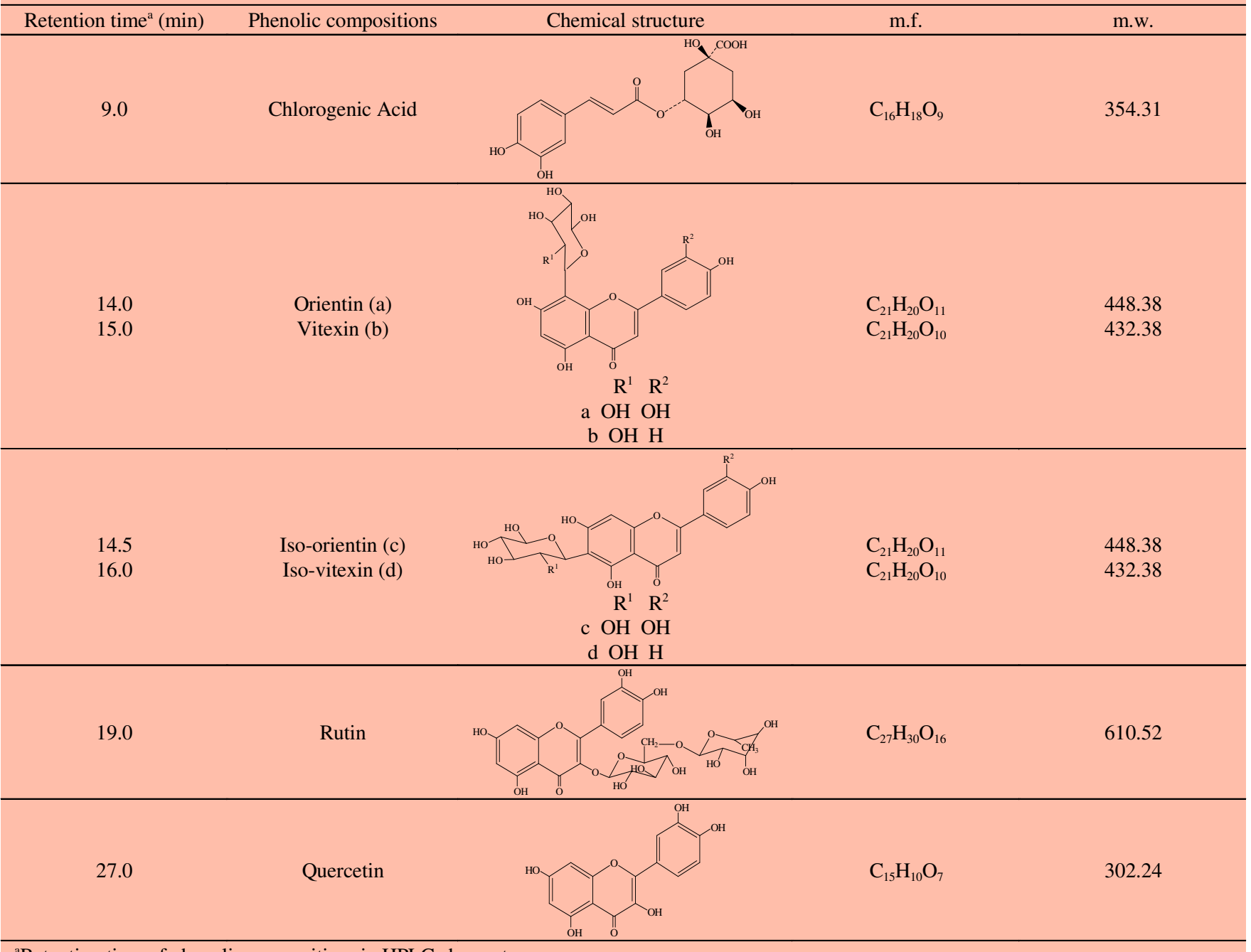

is also known to reduce the risk of hypertension ${ }^{14}$. Besides rutin and quercetin, the other flavonoids like vitexin, isovitexin, orientin and isoorientin are also considered as good antioxidant compounds present in buckwheat (Table-1).

These days, buckwheat sprouts (yellow type grown without light) gained popularity due to the functional compounds present in them and are considered as a new vegetable in Korea $^{15}$. Moreover, a Japanese research group also reported that buckwheat sprouts (green type, grown with sunlight) are a good food material potentially used for human health due to high levels of phenolic and anthocyanin contents and the correlation between antioxidant activity and rutin ${ }^{16}$. However, the results were varied in different researches. This variation could be due to the fact that the buckwheat phenolics can be influenced by geographic origin of seeds as well as environmental conditions. Likewise, phenolic contents in buckwheat can also be influenced by solar radiation ${ }^{17}$, photoperiods cultivation time and different practices ${ }^{18}$. The aim of this study was to evaluate common ('Kitawase') and Tartary buckwheat ('Hokkai T 8', 'Hokkai T 9' and 'Hokkai T 10') cultivated in soil- and soilless-grown practices and compared their ability in plant growth and phenolic metabolites at 7 and 10 days after sowing (DAS).

\section{EXPERIMENTAL}

HPLC-grade acetonitrile and methanol were purchased from Wako Pure Chemical Industries (Osaka, Japan). Authentic compounds such as chlorogenic acid and flavonoids involving C-glycosylflavones (orientin, isoorientin vitexin and isovitexin), rutin and quercetin were supplied by Extrasynthèse (Genay, France) for external standards.

Preparation of plant materials: Common ('Kitawase') and Tartary buckwheat ('Hokkai T 8', 'Hokkai T 9' and 'Hokkai $\mathrm{T} 10^{\prime}$ ) were used to compare their phenolic metabolites in seed sprouts grown soil and soilless practices.

With soil: Pretreated seeds ( $20 \mathrm{~g})$ with $10 \% \mathrm{NaClO}$ were sown in a paper pack $(10 \times 10 \times 4 \mathrm{~cm})$ previously packed with saw dust $(20 \mathrm{~g})$ and sterilized with boiling water. The seeds were then covered with potting soil (20 g, JA Hokuren PotAce, Japan).

Without soil: Buckwheat seeds ( $8 \mathrm{~g}$ ) previously sterilized with $10 \%(\mathrm{v} / \mathrm{v})$ sodium hypochlorite $(\mathrm{NaClO})$ for $3 \mathrm{~h}$ were sown in plastic pots $(6.5 \times 6.5 \times 15 \mathrm{~cm})$.

After germination in a growth chamber at $30{ }^{\circ} \mathrm{C}$ for 2 days in the dark, the seedlings were transferred to the greenhouse and cultured under black plastic shading $(95 \%$ cut off 
sunlight) by hand-watering for the soil-sprouts and by automatic water-supply system (4 L every $2 \mathrm{~h}$ ) for the soillesssprouts. The cotyledons of buckwheat sprouts were harvested at 7 and 10 days after sowing (DAS) and immediately measured and weighted their height and fresh weight (FW). After lyophilization, seed sprouts were weighted their dry weight (DW), ground with mortar and pestle and individually stored in a plastic bottle with a lid in desiccator until chemical analysis.

\section{Extraction and quantification of phenolic compounds:} Powdered sprouts $(10 \mathrm{mg})$ were extracted by mixing $1 \mathrm{~mL}$ $\mathrm{MeOH}$ solution containing $10 \%$ phosphoric acid $[0.1 \%(\mathrm{v} / \mathrm{v})]$ in a $2 \mathrm{~mL}$ Eppendorf tube. The mixture was incubated at $37^{\circ} \mathrm{C}$ in an incubator for $3 \mathrm{~h}$ and then centrifuged at 1,000 $\mathrm{g}$ for $5 \mathrm{~min}$. The supernatant was filtered through a $0.5 \mu \mathrm{m}$ poresize PTFE hydrophobic filter (Advantec, Tokyo, Japan). The filtrate was analyzed by using a Shimadzu Class-VP HPLC system (Kyoto, Japan) equipped with a Capcell PAK ODS column $(250 \times 4.6 \mathrm{~mm}$, particle size $5 \mu \mathrm{m}$; Shiseido, Tokyo, Japan). A variable-wavelength UV detector set at $350 \mathrm{~nm}$. In the gradient mode (flow-rate, $1 \mathrm{~mL} / \mathrm{min}$; column oven temperature, $40{ }^{\circ} \mathrm{C}$ ), the mobile phase consisted of (A) methanol: water:acetic acid (v/v/v, 5:92.5:2.5) and (B) methanol:water: acetic acid $(95: 2.5: 2.5)^{21}$. Quantities were individually determined by comparison of HPLC peak areas with the peak area of external standards and expressed as $\mathrm{mg} / \mathrm{g}$ of dry weight (DW).

\section{RESULTS AND DISCUSSION}

Plant growth: In common buckwheat sprouts ('Kitawase'), the height of cotyledon in soil-grown practice was 7.7 and
$10.2 \mathrm{~cm}$, whereas in soilless-grown practice was 12.8 to 15.2 $\mathrm{cm}$ at 7 and 10 DAS, respectively (Table-1). However, the fresh and dry weight of 'Kitawase' in the soil-grown practice were higher than that in soilless-grown practice. That is, the growth of common buckwheat sprouts under soilless-grown practice was very fast without getting plant weights. This result is explained by the water content having much higher than that under soil-grown practice. Moreover, present results indicated that soilless-grown sprouts of 'Kitawase' are consider as more advantageous than soil-grown sprouts with respect to height of the plant. In our previous study, the dry weight of 'Kitawase' sprout grown without soil exhibited 3 and $2.1 \mathrm{~g} /$ pot at 7 and 10 DAS, respectively, which were higher (50 and $10 \%)$ compared to those of the present study.

On the other hand, the plant growth in all Tartary varieties of buckwheat sprouts grown under soilless practice in all cultivars of tartary buckwheat were higher than that of soilgrown practice, whereas fresh and dry weights were lower in soilless-grown practice as shown in 'Kitawase', but the fresh and dry weights in 'Hokkai T9' were reversed, higher in soillessthan soil-grown practices (Table-2). The differences in growth rates of common and Tartary sprouts between soil-grown and soilless-grown practices gave an idea that buckwheat sprouts is good for salad in soilless practice. In this study, plant growths of soilless-grown buckwheats were monitored by supplying the appropriate amount of water spray when compared to soilgrown plants which exhibited higher growth. Kim et al. ${ }^{12}$ suggested that water-spraying is better method for cultivation of buckwheat sprouts. However, soilless-grown practice method for buckwheat sprouts showed better plant growth and by using this culture system the present result could show an increase

TABLE-2

EFFECTS OF DIFFERENT PRACTICE ON PLANT GROWTH ${ }^{\mathrm{A}}$ IN THE 7 AND 10 DAY-AFTER-SEEDING OF BUCKWHEAT SPROUTS

\begin{tabular}{|c|c|c|c|c|c|c|}
\hline Cultivar & $\begin{array}{l}\text { Days after } \\
\text { Sowing (d) }\end{array}$ & Practice & $\begin{array}{l}\text { Height } \\
(\mathrm{cm})^{\mathrm{b}}\end{array}$ & $\begin{array}{c}\text { Fresh weight/ } \\
\text { pot }(\mathrm{g})\end{array}$ & $\begin{array}{l}\text { Dry weight/ } \\
\text { pot }(\mathrm{g})\end{array}$ & $\begin{array}{c}\text { Water content } \\
(\%)\end{array}$ \\
\hline \multirow{6}{*}{ Kitawase } & \multirow[t]{2}{*}{7} & Soil-grown & $7.67 \pm 1.37$ & $35.76 \pm 6.47$ & $3.81 \pm 0.37$ & $89.21 \pm 1.03$ \\
\hline & & Soilless-grown & $12.82 \pm 0.42$ & $33.35 \pm 2.29$ & $2.03 \pm 0.41$ & $93.83 \pm 1.73$ \\
\hline & \multirow[t]{2}{*}{10} & Soil-grown & $10.24 \pm 1.11$ & $47.13 \pm 6.78$ & $3.66 \pm 0.48$ & $92.22 \pm 0.41$ \\
\hline & & Soilless-grown & $15.24 \pm 0.71$ & $40.10 \pm 3.68$ & $1.87 \pm 0.16$ & $95.34 \pm 0.07$ \\
\hline & {$[7+10]$} & Soil-grown & $8.95 \pm 1.79$ & $45.19 \pm 13.84$ & $3.86 \pm 0.66$ & $91.07 \pm 1.86$ \\
\hline & Mean $(n=8)$ & Soilless-grown & $14.03 \pm 1.40$ & $36.72 \pm 4.59$ & $1.95 \pm 0.30$ & $94.58 \pm 1.39$ \\
\hline \multirow{6}{*}{ Hokkai T 8} & \multirow[t]{2}{*}{7} & Soil-grown & $6.80 \pm 0.41$ & $31.32 \pm 2.86$ & $4.10 \pm 0.69$ & $86.87 \pm 2.15$ \\
\hline & & Soilless-grown & $8.27 \pm 0.60$ & $22.80 \pm 1.83$ & $2.16 \pm 0.13$ & $90.53 \pm 0.53$ \\
\hline & \multirow[t]{2}{*}{10} & Soil-grown & $8.40 \pm 1.03$ & $34.72 \pm 3.08$ & $3.61 \pm 0.57$ & $89.60 \pm 1.33$ \\
\hline & & Soilless-grown & $10.39 \pm 0.65$ & $27.03 \pm 2.44$ & $1.62 \pm 0.30$ & $93.92 \pm 1.45$ \\
\hline & {$[7+10]$} & Soil-grown & $7.60 \pm 1.12$ & $33.02 \pm 3.30$ & $3.86 \pm 0.64$ & $88.24 \pm 2.21$ \\
\hline & Mean $(n=8)$ & Soilless-grown & $9.33 \pm 1.27$ & $24.91 \pm 3.01$ & $1.89 \pm 0.36$ & $92.22 \pm 2.08$ \\
\hline \multirow{8}{*}{ Hokkai T 9} & \multirow[t]{2}{*}{7} & Soil-grown & $7.94 \pm 0.13$ & $22.15 \pm 2.93$ & $1.78 \pm 0.15$ & $91.94 \pm 0.62$ \\
\hline & & Soilless-grown & $7.91 \pm 0.29$ & $26.57 \pm 3.55$ & $1.78 \pm 0.15$ & $93.18 \pm 1.42$ \\
\hline & \multirow[t]{2}{*}{10} & Soil-grown & $8.48 \pm 0.21$ & $26.25 \pm 2.54$ & $1.69 \pm 0.13$ & $93.54 \pm 0.32$ \\
\hline & & Soilless-grown & $10.25 \pm 0.34$ & $36.23 \pm 3.72$ & $1.62 \pm 0.19$ & $95.53 \pm 0.09$ \\
\hline & {$[7+10]$} & Soil-grown & $8.21 \pm 0.33$ & $24.20 \pm 3.35$ & $1.73 \pm 0.14$ & $92.74 \pm 0.97$ \\
\hline & \multirow{3}{*}{$\begin{array}{c}\text { Mean }(\mathrm{n}=8) \\
7\end{array}$} & Soilless-grown & $9.08 \pm 1.28$ & $31.40 \pm 6.16$ & $1.70 \pm 0.18$ & $94.36 \pm 1.56$ \\
\hline & & Soil-grown & $6.75 \pm 0.30$ & $26.35 \pm 3.48$ & $2.85 \pm 0.29$ & $89.15 \pm 0.32$ \\
\hline & & Soilless-grown & $8.47 \pm 0.11$ & $26.91 \pm 2.90$ & $2.22 \pm 0.24$ & $91.74 \pm 0.25$ \\
\hline \multirow[t]{4}{*}{ Hokkai T 10} & \multirow[t]{2}{*}{10} & Soil-grown & $7.28 \pm 0.60$ & $25.10 \pm 2.26$ & $2.16 \pm 0.12$ & $91.37 \pm 0.79$ \\
\hline & & Soilless-grown & $9.26 \pm 0.92$ & $22.17 \pm 5.47$ & $1.21 \pm 0.32$ & $94.55 \pm 0.24$ \\
\hline & {$[7+10]$} & Soil-grown & $7.01 \pm 0.52$ & $25.73 \pm 2.80$ & $2.50 \pm 0.42$ & $90.26 \pm 1.31$ \\
\hline & Mean $(\mathrm{n}=8)$ & Soilless-grown & $6.61 \pm 1.24$ & $21.55 \pm 2.98$ & $1.71 \pm 0.22$ & $91.95 \pm 1.38$ \\
\hline
\end{tabular}

${ }^{a}$ Mean values \pm S.D. $(n=4) .{ }^{b}$ Mean values \pm S.D. $(n=10)$ 
in plant height of buckwheat sprouts ${ }^{4}$. This clearly revealed that the amount of fresh weight was not directly related to dry weight, but it was proportional to the water content in soillessgrown practices. This study also clearly indicated that the amount of water content play a crucial role in plant growth pattern since the height of soilless-grown common and Tartary buckwheat sprouts were much higher than the soil-grown buckwheat sprouts.

Phenolic contents of buckwheat sprouts: Phenolic metabolites in buckwheat sprouts were identified as chlorogenic acid C-glycosylflavones (orientin, isoorientin, vitexin and isovitexin), rutin and quercetin (Table-3 and Fig. 1). Chlorogenic acid was found as similar amounts between in common and Tartary buckwheat sprouts and its amount was higher in soilless- grown sprouts than that of soil-grown sprouts. Quercetin was quantified as extremely low level both in common and Tartary buckwheat sprouts. Interestingly, $C$-glycosylflavones were presented as much as rutin content in common buckwheat sprouts, but they were very low in Tartary buckwheat sprouts. In addition, the total phenolic contents were higher $(16 \%)$ in soilless-grown practice than those in soil-grown practice, but in "Hokkai T10' it was similar or reversed. Chlorogenic acid contents were ranged mean 1.73-3.36 mg/g DW and they were higher in soilless-grown practice than in soil-grown practice at $10 \mathrm{DAS}$ than at 7 DAS. $C$ glycosylflavones (orientin, isoorientin, vitexin and isovitexin) contents in common buckwheat sprouts were found relatively high amounts to rutin which is the highest in developed buckwheat sprouts, but they were very low level in Tartary buckwheat sprouts.

\begin{tabular}{|c|c|c|c|c|c|c|c|c|c|c|}
\hline \multicolumn{11}{|c|}{$\begin{array}{l}\text { TABLE-3 } \\
\text { EFFECTS OF DIFFERENT PRACTICE ON PHENOLIC CONTENT (mg g-1 DW })^{\mathrm{a}} \\
\text { IN THE } 7 \text { AND } 10 \text { DAY AFTER-SEEDING OF BUCKWHEAT SPROUTS }\end{array}$} \\
\hline Cultivar & $\begin{array}{c}\text { Days } \\
\text { after } \\
\text { sowing }\end{array}$ & Practice & $\begin{array}{l}\text { Chloro } \\
\text { genic acid }\end{array}$ & Orientin & Iso-orientin & Vitexin & Iso-vitexin & Rutin & Quercetin $^{\mathrm{b}}$ & Total \\
\hline \multirow{6}{*}{ 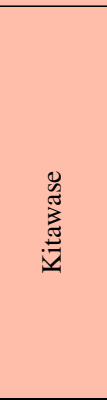 } & 7 & $\begin{array}{l}\text { Soil- } \\
\text { grown }\end{array}$ & $1.62 \pm 0.14$ & $3.85 \pm 0.13$ & $4.48 \pm 0.16$ & $4.25 \pm 0.04$ & $4.83 \pm 0.03$ & $3.29 \pm 0.16$ & $0.025 \pm 0.012$ & $22.35 \pm 0.28$ \\
\hline & & $\begin{array}{l}\text { Soilless- } \\
\text { grown }\end{array}$ & $2.02 \pm 0.26$ & $6.43 \pm 0.31$ & $8.14 \pm 0.39$ & $5.98 \pm 0.41$ & $6.80 \pm 0.47$ & $6.25 \pm 0.41$ & $0.013 \pm 0.001$ & $35.63 \pm 2.15$ \\
\hline & 10 & $\begin{array}{l}\text { Soil- } \\
\text { grown }\end{array}$ & $1.84 \pm 0.04$ & $5.05 \pm 0.06$ & $6.27 \pm 0.06$ & $5.15 \pm 0.08$ & $5.89 \pm 0.05$ & $6.29 \pm 0.14$ & $0.060 \pm 0.025$ & $30.55 \pm 0.10$ \\
\hline & & $\begin{array}{l}\text { Soilless- } \\
\text { grown }\end{array}$ & $2.07 \pm 0.09$ & $7.33 \pm 0.51$ & $8.97 \pm 0.61$ & $6.45 \pm 0.21$ & $7.48 \pm 0.19$ & $7.37 \pm 0.28$ & $0.046 \pm 0.010$ & $39.72 \pm 1.76$ \\
\hline & {$[7+10]$} & $\begin{array}{l}\text { Soil- } \\
\text { grown }\end{array}$ & $1.73 \pm 0.14$ & $4.45 \pm 0.60$ & $5.38 \pm 0.90$ & $4.70 \pm 0.45$ & $5.36 \pm 0.53$ & $4.79 \pm 1.61$ & $0.043 \pm 0.024$ & $26.45 \pm 4.38$ \\
\hline & $\begin{array}{l}\text { Mean } \\
(\mathrm{n}=8)\end{array}$ & $\begin{array}{l}\text { Soilless- } \\
\text { grown }\end{array}$ & $2.04 \pm 0.17$ & $6.88 \pm 0.58$ & $8.56 \pm 0.61$ & $6.22 \pm 0.37$ & $7.14 \pm 0.46$ & $6.81 \pm 0.68$ & $0.029 \pm 0.017$ & $37.67 \pm 2.84$ \\
\hline \multirow{6}{*}{ 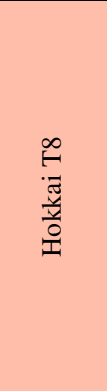 } & 7 & $\begin{array}{c}\text { Soil- } \\
\text { grown }\end{array}$ & $1.72 \pm 0.14$ & $0.10 \pm 0.01$ & $0.10 \pm 0.01$ & $0.66 \pm 0.05$ & $0.64 \pm 0.06$ & $27.82 \pm 2.09$ & $0.045 \pm 0.009$ & $31.08 \pm 2.36$ \\
\hline & & $\begin{array}{l}\text { Soilless- } \\
\text { grown }\end{array}$ & $2.96 \pm 0.24$ & $0.27 \pm 0.03$ & $0.27 \pm 0.04$ & $1.08 \pm 0.10$ & $1.12 \pm 0.10$ & $30.32 \pm 2.20$ & $0.074 \pm 0.024$ & $36.09 \pm 2.69$ \\
\hline & 10 & $\begin{array}{l}\text { Soil- } \\
\text { grown }\end{array}$ & $2.92 \pm 0.18$ & $0.15 \pm 0.02$ & $0.12 \pm 0.02$ & $0.64 \pm 0.03$ & $0.64 \pm 0.05$ & $29.89 \pm 1.35$ & $0.061 \pm 0.030$ & $34.41 \pm 1.56$ \\
\hline & & $\begin{array}{l}\text { Soilless- } \\
\text { grown }\end{array}$ & $3.77 \pm 0.48$ & $0.28 \pm 0.01$ & $0.26 \pm 0.01$ & $1.05 \pm 0.06$ & $1.08 \pm 0.06$ & $33.59 \pm 2.11$ & $0.058 \pm 0.006$ & $40.09 \pm 2.61$ \\
\hline & {$[7+10]$} & $\begin{array}{l}\text { Soil- } \\
\text { grown }\end{array}$ & $2.32 \pm 0.66$ & $0.13 \pm 0.03$ & $0.11 \pm 0.02$ & $0.65 \pm 0.04$ & $0.64 \pm 0.05$ & $28.85 \pm 1.97$ & $0.053 \pm 0.022$ & $32.74 \pm 2.57$ \\
\hline & $\begin{array}{l}\text { Mean } \\
(\mathrm{n}=8)\end{array}$ & $\begin{array}{l}\text { Soilless- } \\
\text { grown }\end{array}$ & $3.36 \pm 0.56$ & $0.27 \pm 0.03$ & $0.27 \pm 0.03$ & $1.07 \pm 0.08$ & $1.10 \pm 0.08$ & $31.96 \pm 2.66$ & $0.066 \pm 0.019$ & $38.09 \pm 3.26$ \\
\hline \multirow{6}{*}{ 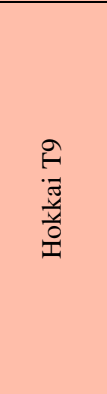 } & 7 & $\begin{array}{l}\text { Soil- } \\
\text { grown }\end{array}$ & $1.49 \pm 0.11$ & $0.039 \pm .005$ & $0.051 \pm 0.007$ & $0.58 \pm 0.02$ & $0.48 \pm 0.02$ & $33.78 \pm 2.12$ & $0.47 \pm 0.15$ & $36.89 \pm 2.31$ \\
\hline & & $\begin{array}{l}\text { Soilless- } \\
\text { grown }\end{array}$ & $2.64 \pm 0.09$ & $0.15 \pm 0.02$ & $0.16 \pm 0.03$ & $1.01 \pm 0.09$ & $1.01 \pm 0.09$ & $39.01 \pm 2.60$ & $0.12 \pm 0.04$ & $47.11 \pm 2.84$ \\
\hline & 10 & $\begin{array}{l}\text { Soil- } \\
\text { grown }\end{array}$ & $2.62 \pm 0.30$ & $0.090 \pm 0.006$ & $0.066 \pm 0.004$ & $0.61 \pm 0.03$ & $0.49 \pm 0.02$ & $42.93 \pm 2.07$ & $0.18 \pm 0.06$ & $47.00 \pm 2.26$ \\
\hline & & $\begin{array}{l}\text { Soilless- } \\
\text { grown }\end{array}$ & $2.90 \pm 0.11$ & $0.17 \pm 0.02$ & $0.19 \pm 0.02$ & $1.05 \pm 0.09$ & $1.04 \pm 0.09$ & $47.93 \pm 4.44$ & $0.12 \pm 0.04$ & $53.41 \pm 4.75$ \\
\hline & {$[7+10]$} & $\begin{array}{l}\text { Soil- } \\
\text { grown }\end{array}$ & $2.06 \pm 0.64$ & $0.064 \pm 0.028$ & $0.06 \pm 0.01$ & $0.60 \pm 0.03$ & $0.49 \pm 0.02$ & $38.35 \pm 5.26$ & $0.33 \pm 0.18$ & $41.95 \pm 4.80$ \\
\hline & $\begin{array}{l}\text { Mean } \\
(\mathrm{n}=8)\end{array}$ & $\begin{array}{l}\text { Soilless- } \\
\text { grown }\end{array}$ & $2.77 \pm 0.17$ & $0.16 \pm 0.02$ & $0.18 \pm 0.03$ & $1.03 \pm 0.08$ & $1.03 \pm 0.09$ & $43.47 \pm 5.84$ & $0.12 \pm 0.04$ & $48.76 \pm 6.15$ \\
\hline \multirow{6}{*}{ 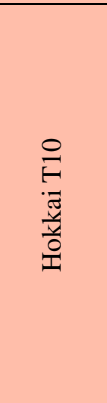 } & 7 & $\begin{array}{l}\text { Soil- } \\
\text { grown }\end{array}$ & $1.31 \pm 0.08$ & $0.049 \pm 0.002$ & $0.038 \pm 0.002$ & $0.43 \pm 0.02$ & $0.33 \pm 0.01$ & $34.32 \pm 1.46$ & $0.17 \pm 0.04$ & $36.64 \pm 1.59$ \\
\hline & & $\begin{array}{l}\text { Soilless- } \\
\text { grown }\end{array}$ & $2.76 \pm 0.13$ & $0.091 \pm 0.002$ & $0.062 \pm 0.002$ & $0.51 \pm 0.01$ & $0.44 \pm 0.02$ & $34.63 \pm 0.51$ & $0.28 \pm 0.15$ & $38.77 \pm 0.046$ \\
\hline & 10 & $\begin{array}{l}\text { Soil- } \\
\text { grown }\end{array}$ & $2.31 \pm 0.17$ & $0.11 \pm 0.01$ & $0.057 \pm 0.003$ & $0.46 \pm 0.04$ & $0.36 \pm 0.01$ & $40.12 \pm 1.48$ & $0.29 \pm 0.09$ & $43.70 \pm 1.39$ \\
\hline & & $\begin{array}{l}\text { Soilless- } \\
\text { grown }\end{array}$ & $3.37 \pm 0.13$ & $0.13 \pm 0.02$ & $0.089 \pm 0.020$ & $0.51 \pm 0.03$ & $0.46 \pm 0.04$ & $37.92 \pm 2.13$ & $0.26 \pm 0.05$ & $42.75 \pm 2.13$ \\
\hline & {$[7+10]$} & $\begin{array}{l}\text { Soil- } \\
\text { grown }\end{array}$ & $1.81 \pm 0.55$ & $0.079 \pm 0.032$ & $0.048 \pm 0.010$ & $0.45 \pm 0.03$ & $0.34 \pm 0.02$ & $37.22 \pm 3.39$ & $0.23 \pm 0.09$ & $40.17 \pm 4.02$ \\
\hline & $\begin{array}{c}\text { Mean } \\
(\mathrm{n}=8)\end{array}$ & $\begin{array}{l}\text { Soilless- } \\
\text { grown }\end{array}$ & $3.06 \pm 0.35$ & $0.11 \pm 0.03$ & $0.075 \pm 0.020$ & $0.51 \pm 0.02$ & $0.45 \pm 0.03$ & $36.28 \pm 2.27$ & $0.27 \pm 0.10$ & $40.76 \pm 2.56$ \\
\hline
\end{tabular}

${ }^{\mathrm{a}}$ Mean values \pm S.D. $(n=4) .{ }^{\mathrm{b}}$ Quercetin: it contains substantially less detectable amounts of the quercetin that is associated with aglycone of rutin 


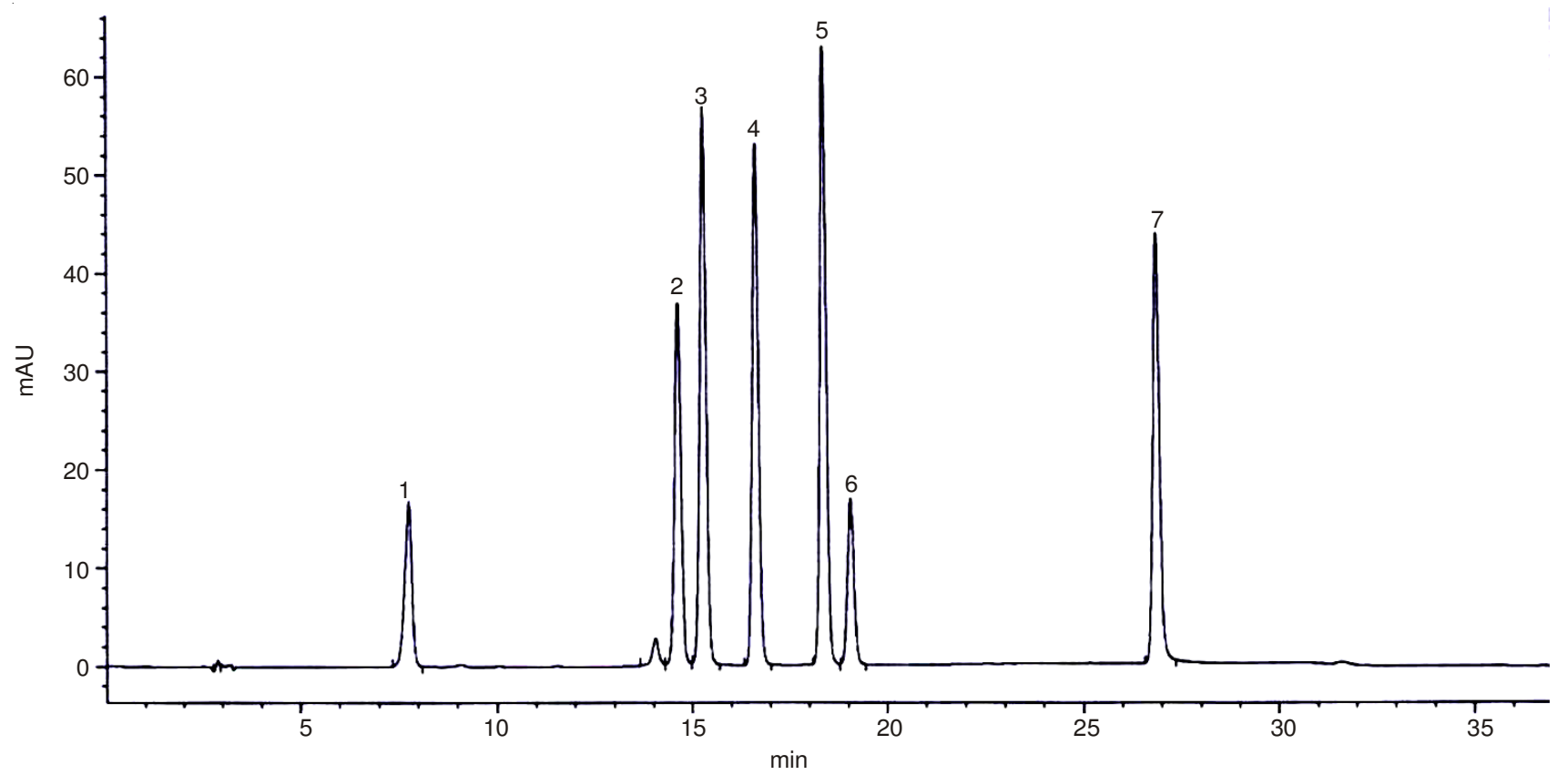

Fig. 1. HPLC profiles of phenolic metabolites present in buckwheat. Peak numbers refer to the phenolic metabolites listed in Table-1. Peak No. 1, Chlorogenic acis; 2, Orientin; 3, Iso-orientin; 4, Vitexin; 5, Iso-vitexin; 6, Rutin; 7, Quercetin

Rutin level is very important in buckwheat plants to evaluate its functionality such as anti-blood pressure (hypertention). Rutin content in common buckwheat sprouts is similar or low level ranging mean 4.79-6.81 mg/g dry weight (soil-grown and soilless-grown, respectively) compared to C-glycosylflavones, whereas it showed marginal high amounts in Tartary buckwheat sprouts ranging mean $28.85-43.47 \mathrm{mg} / \mathrm{g}$ dry weight (soil-grown 'Hokkai T8' and soilless-grown 'Hokkai T9', respectively). The amount of rutin in all types of buckwheat sprouts with soilless practice at 7 DAS were higher than those in buckwheat sprouts with soil practice and amounted to 6.25, 30.32, 39.01, 34.63 mg/g DW in 'Kitawase', 'Hokkai T8', 'Hokkai T 9' and 'Hokkai T10', respectively. Orientin, isoorientin, vitexin and isovitexin contents were higher at 10 DAS compared to 7 DAS. After 7 day the amount of orientin, isoorientin, vitexin, isovitexin and quercetin in seed sprouts of 'Hokkai T 8', 'Hokkai T 9' and 'Hokkai T 10' were found at very low levels and slightly decreased after prolonging the cultivation time to 10 DAS. Furthermore, the rutin was the major component in Tartary buckwheat sprouts when grown in soilless practices both at 7 and 10 DAS. Watanabe and Ito ${ }^{21}$ and Fabjan et al. ${ }^{3}$ claimed that flavonoid contents in the seed sprouts of common buckwheat vary depend on the organs and plant samples ${ }^{19,20}$. In the present study, the flavonoid contents greatly increased by prolonging the growth time both in soil- and soilless-grown practices, especially in the case of rutin. Park et al. ${ }^{20}$ also reported the significant variation in the rutin content in Tartary buckwheat collected from different conditions ${ }^{21}$. In the present study, the total phenolic content in common and Tartary buckwheat sprouts with soilless-grown practice was varied and comparatively higher than those of soil-grown practice. This variation in the concentration of total phenolic contents among the cultivars could be due to the fact that exposure to light and also the age of the buckwheat sprouts affects the phenolic and the flavonoids composition of buck- wheat sprouts ${ }^{18}$. However, in common cultivar the synthesis of orientin, isoorientin, vitexin and isovitexin (6.43 and 7.33, 8.14 and $8.97,5.98$ and $6.45,6.80$ and $7.48 \mathrm{mg} / \mathrm{g}$ dry weight at 7 and $10 \mathrm{DAS}$, respectively) were found in soil-grown practice, even though the production of quercentin slightly increased from 0.013 to $0.046 \mathrm{mg} / \mathrm{g}$ dry weight.

Buckwheat is known as an origin plant of rutin known for its medicinal importance ${ }^{22}$. It was reported that chlorogenic acid has a similar biosynthesis pathway as rutin and quercitrin; accumulation of chlorogenic acid is apparently not affected by the synthesis of quercetin and cyanidin-3-galactoside ${ }^{23}$. Soilless-grown buckwheats showed higher accumulation of rutin and other flavonoids. However, the exact reason responsible for the increase in components of the flavonoids and phenolic compounds in buckwheat sprouts is not clear, so it was considered that further attention required study deeply by analyzing the carbohydrates, fatty acids and vitamin components in their early developmental stage. The diet and health value of the rutin in buckwheat seeds has received an increased attention in recent years. Compared to rutin, chlorogenic acid and quercetin are lesser known even though they are present in the buckwheat sprouts. Quercetin is a flavonoid molecule ubiquitous in nature and used for the synthesis of anti-cancer agent, including cell cycle regulation, interaction with type II estrogen binding sites and tyrosine kinase inhibition ${ }^{24}$.

\section{Conclusion}

The plant growth in all common and Tartary varieties of buckwheat sprouts was better in soilless-grown practice than in soil-grown practice. However, water content represented approximately $92 \%$ in common cultivar when seeding at soilgrown practice, but it was marginally higher of about 93-94.5 $\%$ in Tartary cultivars sprouts when cultivated at 7 and 10 DAS. It is necessary to evaluate and measure phenolic compounds including vitexin, isovitexin, orientin isoorientin and quercetin 
together with rutin for a potential functionality with common buckwheat sprouts because of relatively high amounts. Rutin is considered as an important indicator of the nutritional quality of buckwheat seeds than other phenolics (chlorogenic acids, vitexin, isovitexin, orientin isoorientin and quercetin). In the present study, this result insisted that soilless-grown practice is better to get rutin as well as other phenolic compounds both in common and Tartary buckwheat sprouts, particularly harvested at 10 DAS than at 7 DAS. Overall through this research, it is suggested that soilless-grown practice is good to both common and Tartary buckwheat sprouts and represent an excellent method to harvest nutritional sources like rutin in early days.

\section{ACKNOWLEDGEMENTS}

This project was supported by the Deanship of Scientific Research College of Science Research Centre, King Saud University.

\section{REFERENCES}

1. W.L. Davis and S.B. Matthew, Altern. Med. Rev., 5, 196 (2000).

2. R.L. Edwards, T. Lyon, S.E. Litwin, A. Rabovsky, J.D. Symons and T. Jalili, J. Nutr., 137, 2405 (2007).

3. N. Fabjan, J. Rode, I.J. Kosir, Z. Wang, Z. Zhang and I. Kreft, J. Agric. Food Chem., 51, 6452 (2003).

4. FAO, FAOSTAT-agriculture. Food and Agriculture Organisation of the United Nations.<http://faostat.fao.org > Last Accessed 21.11.11 (2011).

5. J.B. Harborne and C.A. Williams, Phytochemistry, 55, 481 (2000).

6. B. Havsteen, Biochem. Pharmacol., 32, 1141 (1983).
7. M. Holasova, V. Fiedlerova, H. Smrcinova, M. Orsak, J. Lachman and S. Vavreinova, Food Res. Int., 35, 207 (2002).

8. S.J. Jackson and R.C. Venema, J. Nutr., 136, 1178 (2006).

9. J. Yoo, Y. Kim, S.-H. Yoo, G.E. Inglett and S. Lee, Food Chem., 132, 2107 (2012).

10. L. Alvarez-Jubete, H. Wijngaard, E.K. Arendt and E. Gallagher, Food Chem., 119, 770 (2010).

11. S.L. Kim, K.S. Youngm, J.J. Hwang, S.K. Kim, H.S. Hur and C.H. Park, Fagopyrum, 18, 49 (2001).

12. S.L. Kim, S.K. Kim and C.H. Park, Food Res. Int., 37, 319 (2004)

13. S.-J. Kim, I.S.M. Zaidul, T. Maeda, T. Suzuki, N. Hashimoto, S. Takigawa, T. Noda, C. Matsuura-Endo and H. Yamauchi, Sci. Horticul., 115, 13 (2007).

14. S.J. Kim, C. Kawaharada, T. Suzuki, K. Saito, N. Hashimoto, S. Takigawa, T. Noda, C. Matsuura-Endo and H. Yamauchi, Food Sci. Technol. Res., 12, 199 (2006)

15. C. Kupper, Gastroenterology, 128, S121 (2005).

16. C. Manach, A. Scalbert, C. Morand, C. Remesy and L. Jimenez, Am. J. Clin. Nutr., 79, 727 (2004).

17. M. Koyama, C. Nakamura and K. Nakamura, J. Food. Sci. Technol., 50, 86 (2013)

18. M.A. Awad, P.S. Wagenmakers and A. de Jager, Sci. Hortic., 88, 289 (2001).

19. S. Pankaja, K.G. Amal, G. Anup, W.J. Cheng, S.R. Ho and H.C. Dong, Afr. J. Biotechnol., 11, 184 (2012).

20. B.J. Park, J.I. Park, K.J. Chang and C.H. Park, Proceedings of the 9th International Symposium on Buckwheat, Prague, pp. 626-629 (2004).

21. M. Watanabe and M. Ito, Jap. Soc. Food Sci. Technol., 50, 32 (2003).

22. A. Weiss and W.P. Hammes, J. Appl. Bot. Food Qual./Angew. Botan., 77, 152 (2003).

23. H.H. Wijngaard and E.K. Arendt, Cereal Chem., 83, 391 (2006).

24. N. Yildzogle-Ari, V.M. Altan, O. Altinkurt and Y. Ozturk, Phytother. Res., 5, 19 (1991). 